\title{
Online Trial Room based on Human Body Shape Detection
}

\author{
D. M. Anisuzzaman ${ }^{1}$, Md. Hosne Al Walid ${ }^{2}$ \\ Department of Computer Science and Engineering, Ahsanullah University of Science and Technology, \\ Dhaka, Bangladesh \\ Email:rajon99@gmail.com¹,walid.iut06@gmail.com² \\ A. F. M. Saifuddin Saif \\ Department of Computer Science, American International University-Bangladesh, Dhaka, Bangladesh \\ Email: saif@aiub.edu
}

Received: 04 December 2018; Accepted: 20 December 2018; Published: 08 February 2019

\begin{abstract}
High returning rate of garments products have become a notable problem for online fashion shopping. This problem is partially caused by using different standards for measuring cloth sizes on different websites. In this research, we have designed a set of equipment to capture images of t-shirts of any color and propose an automatic cloth measurement approach using image processing techniques. A method has been introduced to recognize feature points, which has been used to calculate the cloth sizes. The method has provided a useful and efficient tool for cloth measurement. The photographs have been taken in a controlled environment, and then clothes have been categorized with the proportions of the neck, shoulder, chest width, upper waist, lower waist, and length. In this method, we have measured the t-shirt size for men by calculating the chest width and length of men. For this, a dataset has been created in a specific environment. This method has integrated with a webbased application. We have validated our work by calculating RMSE values.
\end{abstract}

Index Terms-Online trial room, human body shape detection.

\section{INTRODUCTION}

This research has proposed a model by which the size of the t-shirt can be measured from a 2D image. Online trial room based on body shape recognition will be a unique system as there is no other similar system is available currently in Bangladesh. There exists a few works or research paper on this idea. A controlled surrounding is needed for taking photos which is possible for each user to provide by using our proposed web-based application.

With the introduction of smartphones and tablets, we can enjoy online shopping anytime while sitting in any part of the world. Online shopping has certainly replaced the traditional way of shopping for daily goods and clothing. When we choose online shopping, we get the benefit of credibility. Today, almost every online store offers cash on delivery, free shipping, and discounted prices. These online shopping stores eliminate the hassles of parking, getting stuck in traffic jams and standing in long queues for billing. They have also benefited those people who always complain about the shortage of time. This is the reason, a majority of the people have turned to online shopping. Made-to-Measure System (m-t-m) allows customers to create better fitting garments which are suitable for their bodies [1].

We have developed a web based application where people can choose their required size of clothes according to their body shape from a 2D image. The idea is unique according to our country as there is no other application based on this idea right now in Bangladesh. After doing research on various existing online shops we have learned that the measurement of the clothes varies from shop to shop. It is very difficult to choose the required size of clothes according to the customer's clothes size. In our proposed idea, the clothes size of a human being can be measured from a 2D image without physically being present.

\section{RESEARCH BACKGROUND}

There have been some related works in this field specially T-shirt size detection. Four types of people (tall fat, short fat, tall thin and short thin) have been detected from $2 \mathrm{D}$ images by using a proposed method [2]. This recognition has been done by assuming some conditions: the subject must be in a standing position and subject must consist of five segments: two hands, two legs, and torso. The system has extracted the size and the advantage of them from the image. It also has extracted some features of the human body such as length and width. They have used Canny Edge Detection Algorithm in their preprocessing stage and proposed a Semiautomatic Feature Extraction Algorithm.

Feature points on the outline of the human body have been detected by using a proposed systematic method from 2D frontal and side images [3]. An efficient shape coding algorithm has been used to represent the human 
body contour from binary images. They have identified the feature points by evaluating the difference between the coding sequences. They have provided methods for the automatic feature extraction from full body outlines and for the estimation of 2D human models from measurements extracted from the features.

The pictorial structures (PS) method has been developed and applied for human pose estimation [4]. The partial body masks have been evaluated directly at each level of the growing process via shape matching with exemplars, without considering the formation of the hypotheses. Multiple image segmentations have been included at each of the levels of the growing/parsing, to augment existing hypotheses or to introduce ones. A shape parsing method which uses a bottom-up fashion has been presented for the construction and verification of shapes. This research has been done in a different way than the traditional bottom-up parsing by scoring shapes against a set of exemplars using IDSCs.

A model has been proposed to analyze women body scan data (body shape, posture, and weight) and also an expert system has been developed for realigning sizing and pattern development for markets [5]. A body scanner has been used for providing body shapes. BMI (Body Mass Index) has been used for determining body categories such as underweight, normal etc. Reliability checking has been done and for automatic body shape analysis, the software has been developed based on the body shapes identified by experts.

An approach has been proposed to detect viewpoint invariant human by applying example-based body-part detectors [6]. For the head, arms and legs detection 10 sub-classifiers have been integrated. For human action recognition (HAR), stochastic behaviors of body-parts have been utilized. Human body parts have been detected and then the changes of those body parts have been learned for action recognition. Approach to recognize actions have been extended in this research, based on component-wise hidden Markov models.

A new model type for 2D human body has been proposed in [7] which retain the standard part-based structure of classical pictorial structures models. With the expressive power of a detailed 3D model and the computational benefits of a simple 2D part-based model, a new "contour person (CP)" model has been defined. The CP model has also captured the non-rigid deformations of the body that result from articulation. Their 2D model was view-based and there they had only shown examples for frontal bodies.

For the garment industry, a technique of virtual human modeling has been developed with the requirement of two orthogonal views of a human body in two photographs [8]. To obtain the human body contours an efficient segmentation method has been applied to these two photographs. A template-based feature extraction algorithm has been introduced to determine the feature points on the human contours. The Mumford-Shah segmentation technology and the level set formulation have been used for the derivation of the segmentation algorithm, and it has been accelerated by applying multipyramid levels.

The methodology of automatic computer-based measurement has been described for taking anthropometric data [9]. For designing a complete and fully automatic 2D anthropometric system a summarization of needed equipment has been presented here. A new technique for automatic detection of several spatial human body parts has also been proposed. To outline how landmark localization without any other manual steps could be done and to introduce algorithms to solve this problem in $2 \mathrm{D}$ non-contact anthropometry system, a solution has been tried out.

A new approach for defining body shapes of the female has been proposed based on the 2D images analysis [10]. For human interpretation, the improvement of pictorial information has been the main focus of this research. For calculating widths of different body parts, such as waist, hip, bust etc. from 2D images, pixel numbers have been used. The prerequisite of a calibration process or a special camera for capturing images has been eliminated. Plain and dark color dresses along with a light and the plain color background are the only requirement here. A webbased application has been developed for defining body shapes from 2D images and also for collecting additional information such as region, city, and age etc. for building a $\log$ file.

A problem of detecting 3D human shape under clothing has been defined and a solution has been presented that holds a learned model of body shape [11]. The relative pose-independence of body shape model has been exploited to integrate constraints from multiple poses and this has been done by solving for the body pose at each time instant and a single $3 \mathrm{D}$ shape across all time instants. For parts of the unclothed body, a skin detector has also been integrated to provide tight constraints on 3D shape. The idea that: based on the shape of the body gender could be reliably classified has been also showed in this research.

A system has been described for person recognition in indoor images, which can learn from examples [12]. The shape and color-based features have been used to represent images of full-body persons. Different combinations of SVM have been used to carry out the recognition process. The exploration and comparison between k-Nearest Neighbors classifiers and different types of multi-class strategies based on SVMs have been executed. The system works in real time and the experimental results have shown a high recognition rate. It has also indicated the strength of SVM-based classifiers to improve both generalization and run-time performance.

Online fashion shopping has become one of the great sources to purchase clothes. In the very near future, it might be the main source. But buying clothes without a trial room is the main challenge of this field. Our main goal is to overcome this problem that is presenting a virtual system for the online trial room. Our system allows anyone at home to measure their body size from 
2D images and use the results to comfortably shop online. This minimizes the risk of buying unfit clothe. Our system can make the online shopping experience more satisfying. We have measured the shoulder, upper chest, lower chest, waist and hip size from images. Finally, we have used a system to calculate the rest of the measurements and found the suitable cloth size for the customers.

\section{Proposed METHod}

To implement the system we have pre-processed the image to improve the image and suppress unwanted distortion. A controlled domain is needed for data collection which includes a light and plain background color. In this system, we have used Canny Edge Detection Operator to pre-process the image. Different types of algorithms have been used for noise removal. After pre-processing the image, we have extracted some features by using Kollman's distribution algorithm, so that the measurement of the t-shirt as well as the body can be measured. Then we have compared the result to find a better system.

\section{A. Framework}

At first, we have gathered data by using a conventional camera. Then after some pre-processing, we have detected some features. At last, we have found the size of the t-shirt by using our web system. The framework of this method is shown in Fig. 1.

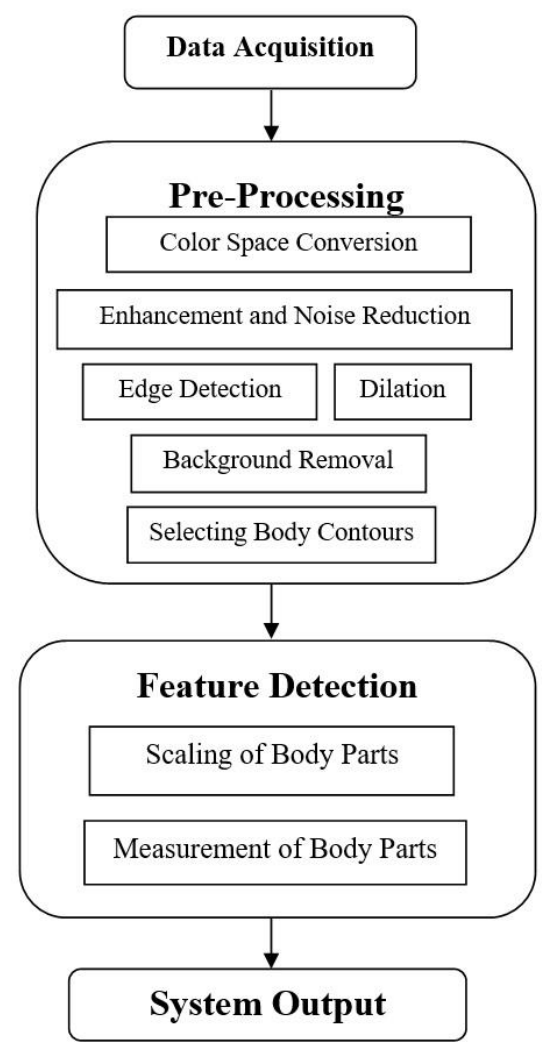

Fig.1. A Block Diagram of "Online Trial Room”

\section{B. Data Acquisition}

In this system, we have used the conventional camera to take an image. For this system, the image must be taken in an environment with some restrictions. We have taken two images: first, background image and then original body image in front of the same background. Some conditions have been provided for capturing images in our proposed model: both background and original body images should be captured in a fixed length and height from the background; background must be light colored and both images should be captured in front of the same background.

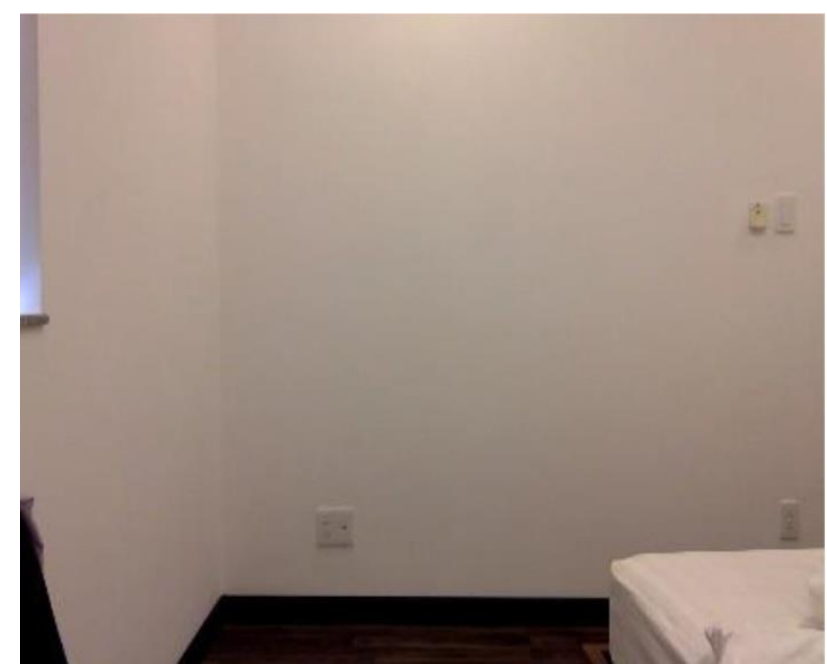

Fig.2. Background Image

We have taken two sample images. First one is only background image (Fig. 2) and the second one is original body image (Fig. 3) taken in front of the same background. Both images have been captured in a fixed distance maintaining a fixed height from the camera lens and background. A light colored background is used so that the system can easily detect the edge of the body and measure the required features of our proposed system.

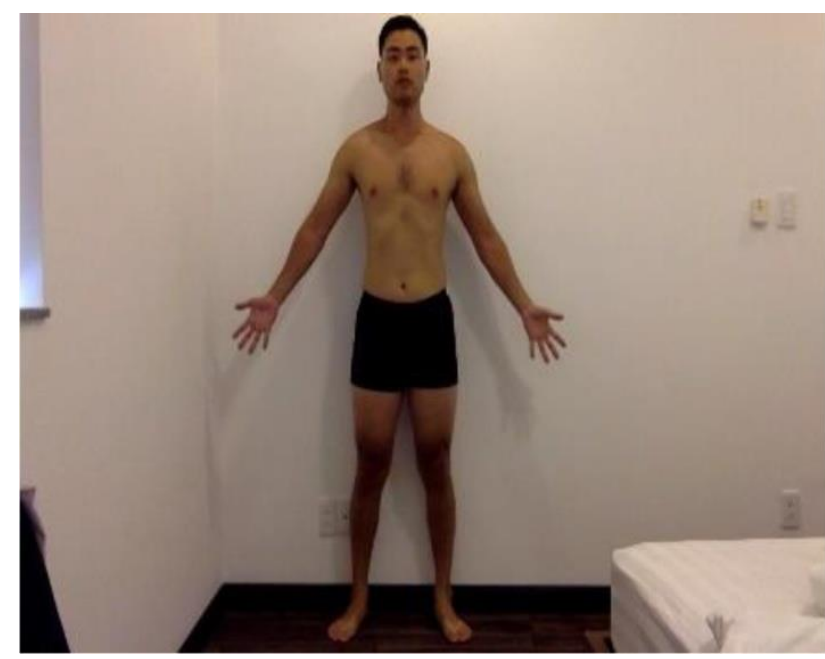

Fig.3. Body image 


\section{Pre-processing}

We have pre-processed our data to overcome unwanted distortions and to enhance some image features important for our further processing.

\section{1) Color Space Conversion}

There are a variety of color spaces, such as RGB, CMY, HSV, HIS, GREYSCALE, BINARY. In this system firstly we have converted RGB color space to HSV color system for shadow removal. Then we have converted it back to RGB color space. Then we have converted it to the Grey Scale color space. The color space conversion Process is shown in Fig. 4.

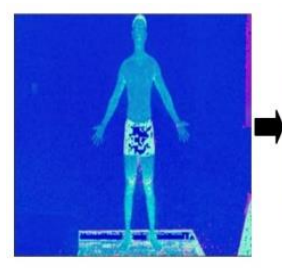

(a)

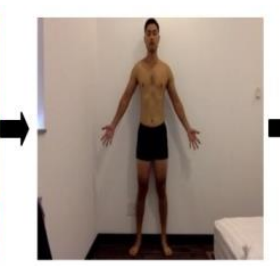

(b)

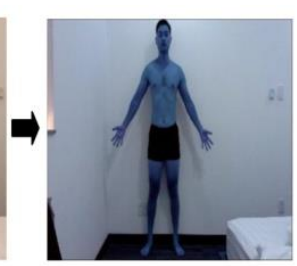

(c)
Fig.4. Color Space Conversion. (a) HSV image; (b) RGB image; (c) Grey Scale image

\section{2) Enhancement and Noise Reduction}

We have used Normalization to enhance the images. Normalization (aka. contrast stretching or histogram stretching) has been used to change the range of pixel intensity values. We have used Median blur and Gaussian blur in this system for the noise reduction. Steps of image enhancement and noise removal are shown in Fig. 5.

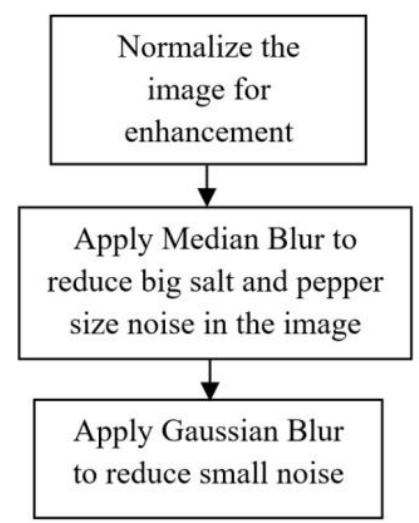

Fig.5. Steps of image enhancement and noise removal

\section{3) Edge Detection}

There are various edge detection algorithms: Sobel, Canny, Prewitt, Roberts and Fuzzy logic method. In this system, we have used the Canny Edge Detection Algorithm to detect the edge of the image. Edge detection has been used for finding the boundaries of objects within images. Though canny edge detection algorithm is a bit time consuming compared to others, it has been used here because it gives a good localization, response and immune to a noisy environment. The edge detection of the human body is shown in Fig. 6.

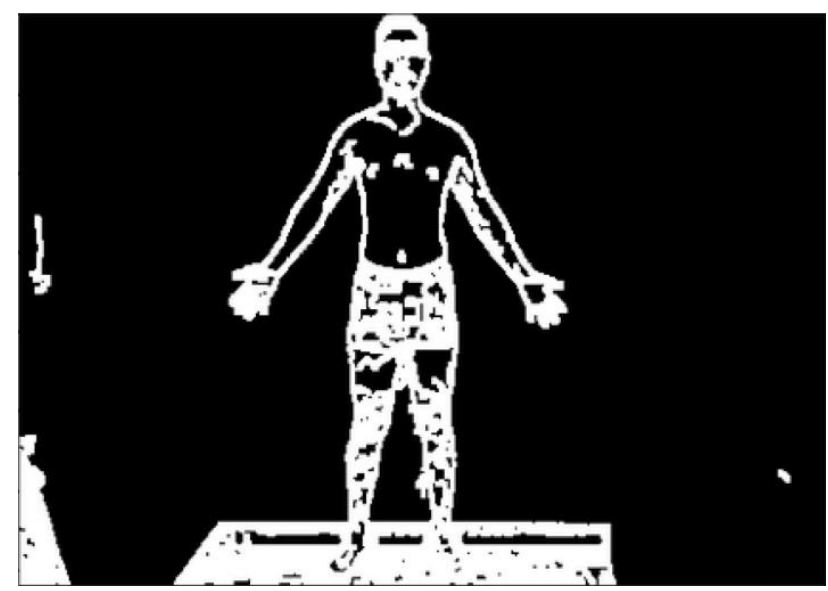

Fig.6. Edge Detection

\section{4) Dilation}

We have used a $7 \times 7$ structuring element for our dilation process. Dilation has been used for background shrinking and foreground thickening.

\section{5) Background Removal}

We have used background removal technique to make our object (human body) ready for body contour selection in the next step. The removed background stage of our input is shown in Fig. 7.

\section{6) Selecting Body Contours}

We have selected body contours for better shape analysis and object detection and recognition. Body contour detection is shown in Fig. 8.

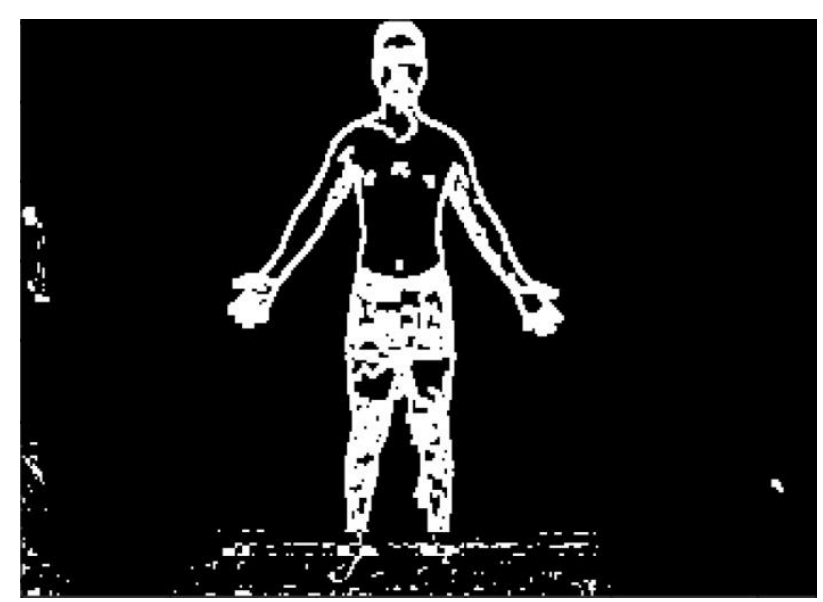

Fig.7. Background Removal 


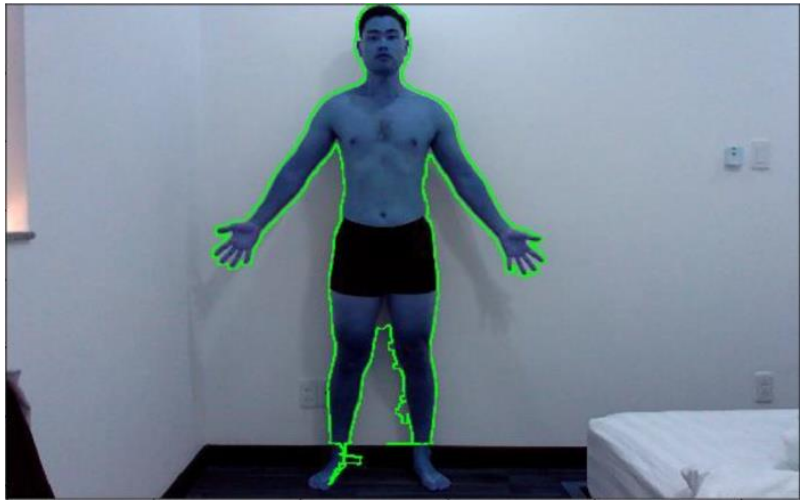

Fig.8. Body Part Detection

\section{Feature Detection}

In this system, neck, shoulder, upper chest, lower chest, waist, and hip sizes are the main features of calculating tshirt size and body shape measurement. We have completed our feature detection process in two steps: scaling of body parts and measurement of body parts.

\section{1) Scaling of Body Parts}

The scanning starts from a starting point which has been chosen at the bottom of the image. We have started at the starting point and continued the scanning up to the top of the image. We have scaled the image into 19 sections to get the required features. This scaling of body parts has been shown in Fig. 9.

\section{2) Measurement of Body Parts}

We only needed to measure neck, shoulder, upper chest, lower chest, waist and hip size in inches. For this reason, we have converted the pixel values into inches by dividing inch with the pixel. Then we have subtracted the minimum pixel value from the maximum pixel value on the selected line to get the size of the body parts. The measurement of the body parts has been shown in Fig. 10.

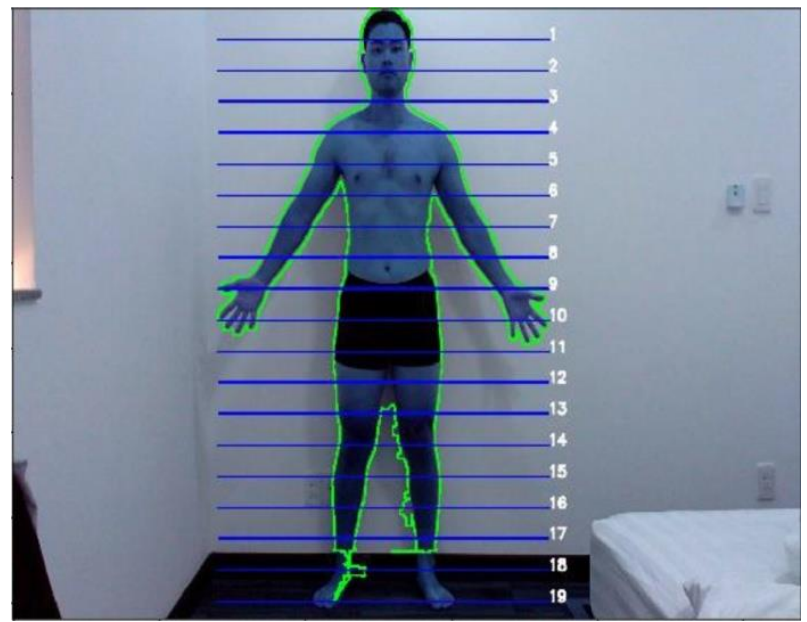

Fig.9. Scaling of Body Parts

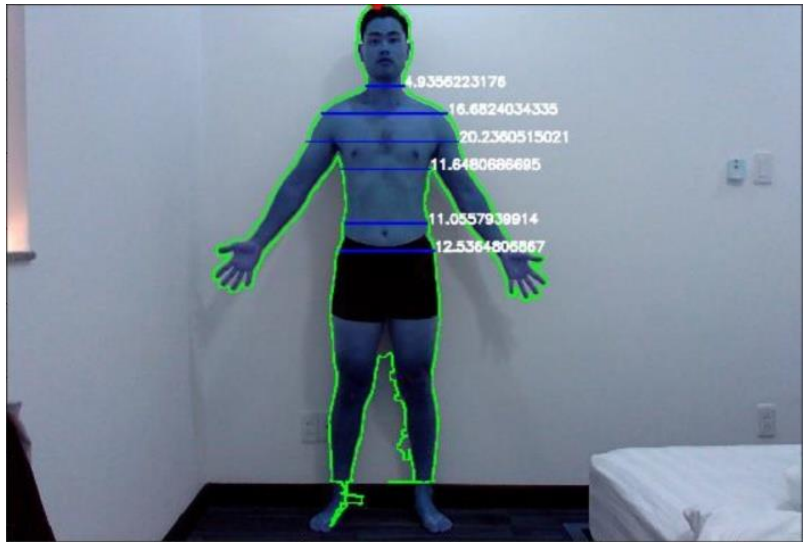

Fig.10. Measuring the parts of the body

\section{E. System Output}

We have used flask framework to create our web page. Flask is a small and powerful web framework for Python. A window appears in the browser (Fig. 11) when the system starts. After clicking the "choose file" button an image can be chosen from any folder of the computer or laptop. After selecting an image one has to click the "upload" button to find the measurement of clothes. After clicking the "upload" button the final output of the system has been shown in the system window (Fig. 12).

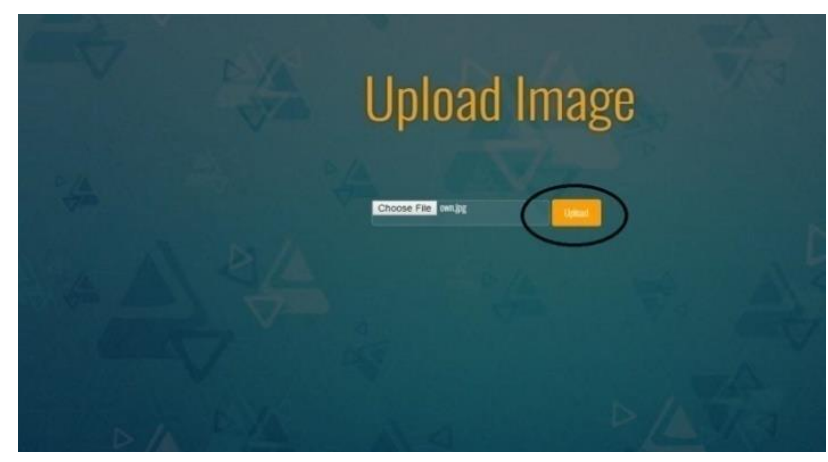

Fig.11. System User Interface

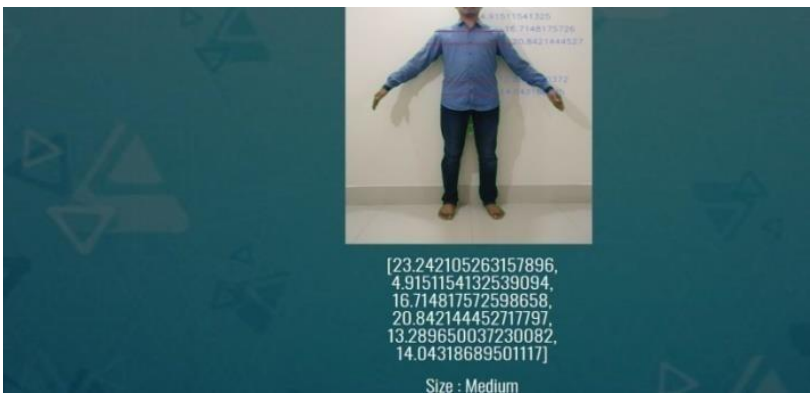

Fig.12. Final Output of our system

\section{RESUlt ANALYSIS AND DisCUSSION}

We did not find any existing dataset for our proposed system. So we have created our own dataset by capturing 
images of random people. But for our proposed system we need a fixed and constant environment for capturing pictures. We have visited some renowned shop's sites in our country for the measurements of clothes such as Ecstacy, Le Reve, Arong, Artisan etc. In this proposed system we have chosen Artisan brand for the standard measurement of t-shirt for men [13]. This standard measurement is shown in Table1.

Table 1. The standard measurement of t-shirt for men

\begin{tabular}{|c|c|c|}
\hline Length (in inch) & Shoulder (in inch) & Size \\
\hline 27 & 16 & Small \\
\hline 28 & 17 & Medium \\
\hline 29 & 18 & Large \\
\hline 30 & 19 & Extra Large \\
\hline
\end{tabular}

A. Comparing Our System Result with Original Measurement

There are few sample data on which we have applied our system. We have managed to collect 20 images of different volunteers and among them, 12 images have shown correct results. We have taken the measurement of clothes manually by a tape with the help of wikihow [14].

The difference between the result of our system and original measurements have been shown in Table 2 (for sample1 and sample2). All values in the table are in inch. The system value outputs of sample1 and sample2 have been shown in Fig. 13 and Fig. 14 respectively.

Table 2. Comparison between the result of our system and original measurement for sample1 and sample2

\begin{tabular}{|c|c|c|c|c|}
\hline \multirow{2}{*}{$\begin{array}{c}\text { Body } \\
\text { Parts }\end{array}$} & $\begin{array}{c}\text { Original } \\
\text { Value }\end{array}$ & $\begin{array}{c}\text { System } \\
\text { value }\end{array}$ & $\begin{array}{c}\text { Original } \\
\text { Value }\end{array}$ & $\begin{array}{c}\text { System } \\
\text { value }\end{array}$ \\
\cline { 2 - 5 } Neck & 6 & 4.915 & 6 & 4.596 \\
\hline Shoulder & 17 & 16.714 & 17 & 14.488 \\
\hline $\begin{array}{c}\text { Upper } \\
\text { chest }\end{array}$ & 22 & 20.842 & 22 & 19.459 \\
\hline $\begin{array}{c}\text { Upper } \\
\text { waist }\end{array}$ & 18 & 13.289 & 16 & 13.289 \\
\hline $\begin{array}{c}\text { Lower } \\
\text { waist }\end{array}$ & 20 & 14.043 & 18 & 14.66 \\
\hline Length & 29 & 28.4 & 29 & 28.1 \\
\hline
\end{tabular}

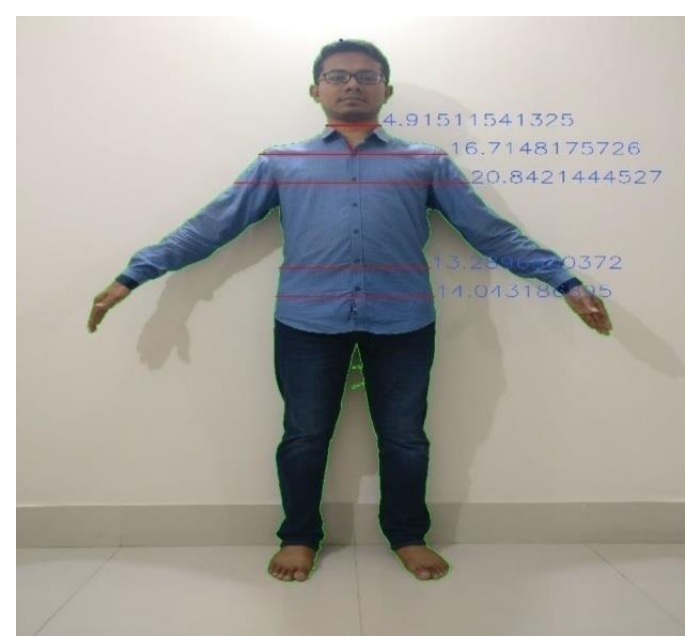

Fig.13. Sample1 Output

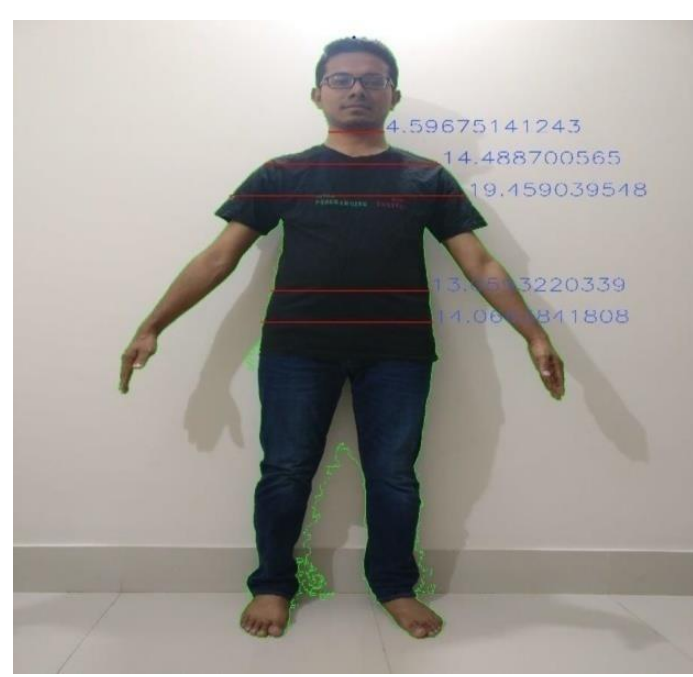

Fig.14. Sample2 Output

\section{B. Error Analysis}

We have used Root Mean Square Error (RMSE) to find the deviation between the original value and the system value. Root Mean Square Error (RMSE) also known as Root Mean Square Deviation measures how much error there is between two data sets. The formula of RMSE has been shown in equation (1).

$$
R M S E=\sqrt{\frac{\sum_{i=1}^{n}\left(O_{i}-P_{i}\right)^{2}}{n}}
$$

Here,

$\mathrm{O}=$ Original value

$\mathrm{P}=$ Predicted value of our system

$\mathrm{n}=$ Total number of sample data

We have calculated the RMSE value for the neck, shoulder, upper waist, lower waist, and length. Table 3 shows the deviation values and RMSE values for different body parts. All values in the table are in inch. Here sample1, sample2, ....sample12 is represented as $\mathrm{S} 1$, $\mathrm{S} 2, \ldots \mathrm{S} 12$ respectively.

Table 3. Deviation values and RMSE values for different body parts

\begin{tabular}{|c|c|c|c|c|c|}
\hline \multirow{2}{*}{$\begin{array}{c}\text { Deviation } \\
\text { Values }\end{array}$} & \multicolumn{5}{|c|}{ Body Parts } \\
\cline { 2 - 6 } & Neck & Shoulder & $\begin{array}{c}\text { Upper } \\
\text { waist }\end{array}$ & $\begin{array}{c}\text { Lower } \\
\text { waist }\end{array}$ & Length \\
\hline S1 & 1.1 & .3 & 4.8 & 3.9 & .6 \\
\hline S2 & 1.5 & 2.6 & 2.8 & 1.9 & .9 \\
\hline S3 & .43 & .6 & 4.8 & 4 & 1.3 \\
\hline S4 & 1 & 1.7 & 4.4 & 3.7 & .9 \\
\hline S5 & .8 & 1.9 & 4.3 & 4.3 & .7 \\
\hline S6 & .4 & .7 & 4.9 & 4.4 & .6 \\
\hline S7 & .7 & 1.6 & 4.7 & 3.7 & 1 \\
\hline S8 & .8 & 1 & 4.5 & 3.6 & 1.1 \\
\hline S9 & .5 & .7 & 3.1 & 3 & .8 \\
\hline S10 & .4 & 1 & 5 & 4.2 & .9 \\
\hline S11 & .2 & 1.3 & 5.3 & 4.2 & .7 \\
\hline S12 & .9 & 2.3 & 4.9 & 4.3 & 1.1 \\
\hline RMSE & .808 & $\mathbf{1 . 4 7 8}$ & $\mathbf{4 . 4 5 4}$ & $\mathbf{3 . 8 3}$ & $\mathbf{. 0 7}$ \\
\hline
\end{tabular}


Here we can see that the RMSE values of upper waist and lower waist are much more than other features (Fig. 15). That means the deviation between the original values and the values of our proposed system for upper and lower waist is much greater, as our proposed system could not find the exact values. RMSE values of upper and lower waist are much higher because of the round shape of clothes.

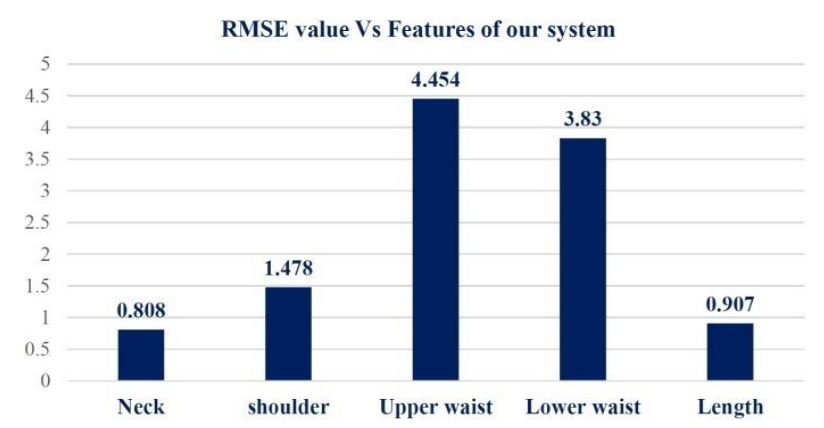

Fig.15. Chart of RMSE value Vs Features of our system

\section{Comparative analysis of our work with existing ones}

Although to the best of our knowledge no work on online trial room has been found in Bangladesh, we have compared our work with the existing similar works where body shape detection has been used. The comparison of our work with existing works has been shown in Table 4 .

From Table 4, we can see that most of the existing works used their own dataset whereas we used our developed one. So, it is really difficult to compare our work with the existing works. Though Result comparison is a very difficult issue as there is no fixed parameter of the existing works but we tried our best to compare our result in terms of RMSE Value and achieved good results (i.e. less error rate) compared to the existing works. With an enriched dataset, we hope to achieve a better result in the future.

Table 4. Comparison of Our Work with Existing Works

\begin{tabular}{|c|c|c|}
\hline Work & Dataset & Result \\
\hline $\begin{array}{l}\text { Five Body Parts (torso, } \\
\text { two hands and two legs) } \\
\text { Detection [2] }\end{array}$ & Own Developed & No numerical comparison has shown \\
\hline $\begin{array}{l}\text { Recognition and Parsing of } \\
\text { the Human Body [4] }\end{array}$ & Baseball Dataset & $\begin{array}{l}\text { Segmentation Scoring: } \\
\text { a vast majority of average errors }<=20 \text { pixels } \\
\text { Joint Position Scoring: } \\
\text { Full body overlap scores: } 0.44 \text { to } 0.84 \\
\text { Average joint position errors: } 10.20 \text { to } 37.96\end{array}$ \\
\hline $\begin{array}{l}\text { View-Invariant Human-Body } \\
\text { Detection [6] }\end{array}$ & $\begin{array}{l}\text { KTH's Database and } \\
\text { HERMES Indoor } \\
\text { Sequence Dataset }\end{array}$ & $\begin{array}{l}\text { KTH Database (according to ROC curve): } \\
\text { Leg detection > 90\% } \\
\text { Head detection < Leg Detection } \\
\text { Arm detection: not very high } \\
\text { HERMES Dataset (according to ROC curve): } \\
\text { Leg, Head and Arm detection < KTH database detection }\end{array}$ \\
\hline $\begin{array}{l}\text { Virtual Human Modeling } \\
\text { from Photographs for the } \\
\text { Garment Industry [8] }\end{array}$ & Own Dataset & $\begin{array}{l}\text { The difference between Tailor and Detected Measurement (unit: } \\
\text { CM): } \\
\text { Height: } 0.72 \text {, Arm Length: } 1.52 \text {, Chest: } 0.05 \text {, Lower Chest: } \\
0.07 \text {, Lower Waist: } 2.23 \text {, Below-ankle Girth: } 1.33 \text { etc. }\end{array}$ \\
\hline Human Body Modelling [9] & $\begin{array}{l}\text { Own Dataset ( } 9 \text { males } \\
\text { and } 2 \text { females) }\end{array}$ & $\begin{array}{l}\text { Average error [Comparison between tape measurement and } \\
\text { developed 2D system (unit: CM)]: } \\
\text { Height: } 2.21 \text {, Neck Circumference: } 3.08 \text {, Chest Circumference: } \\
\text { 3.75, Waist Circumference: } 2.83 \text { and Hips Circumference: } 3.175\end{array}$ \\
\hline $\begin{array}{l}\text { Full-body person recognition } \\
\text { system [12] }\end{array}$ & Own Dataset & $\begin{array}{l}\text { People recognition rates vary from } 45.9 \% \text { to } 98.3 \% \text {, depending } \\
\text { on several parameters and method used }\end{array}$ \\
\hline $\begin{array}{l}\text { Human Body Shape } \\
\text { Detection for Online Trial } \\
\text { Room }\end{array}$ & Own Developed & $\begin{array}{l}\text { Root Mean Square Error (RMSE): } \\
\text { Neck: } 0.808 \text {, Shoulder: } 1.478 \text {, Upper Waist: } 4.454 \text {, Lower } \\
\text { Waist: } 3.83 \text { and Length: } 0.907\end{array}$ \\
\hline
\end{tabular}

\section{Limitations}

To get a proper output we need to follow some conditions. A user has to face some restrictions for capturing a picture: keep the same colour at the background as more than one colour can create a problem for edge detection and has to capture the picture of the user from a fixed distance maintaining a fixed height from the camera lens. Low light can also be problematic for our proposed system. Some problematic situations are shown in Fig. 16 and Fig. 17. 


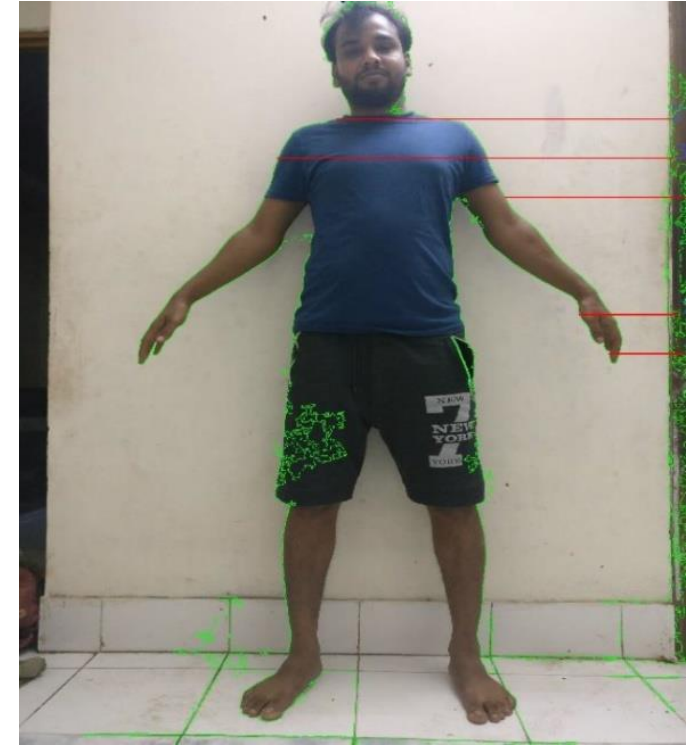

Fig.16.The distance between the object and lens was not accurate

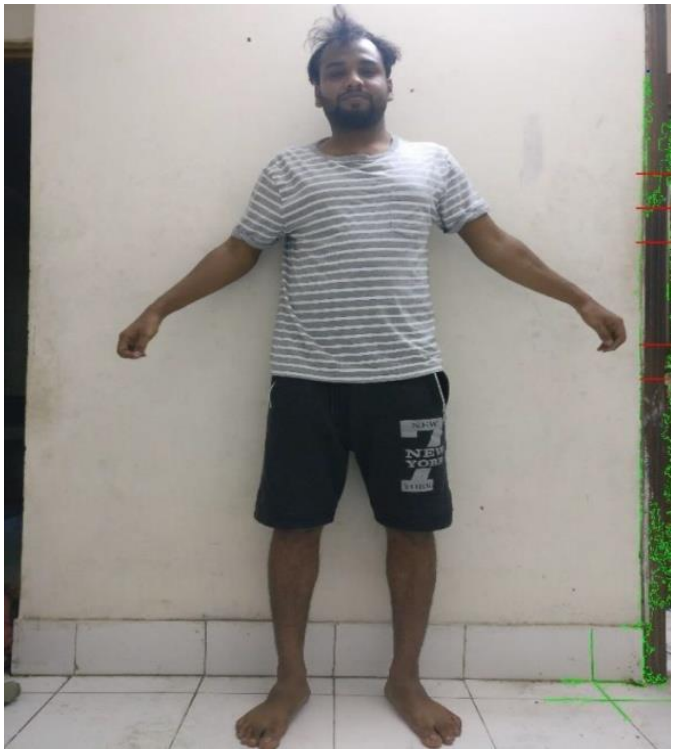

Fig.17. Same background and dress colour

\section{CONCLUSION}

Now a day apparel industries are using computers, especially for manufacturing and process control functions. Online trial room based on body shape recognition is a unique system proposal as there is no other similar system available currently in Bangladesh. As we had inadequate data on which we could apply our system it was not actually possible to find the highest accuracy of our proposed system.

In future we have to create a sufficient dataset following the restriction strictly. Then we will apply our proposed system to the dataset to test and find the accuracy of our system. In this proposed system, we have extracted five features, but have used only two features for measuring the size of t-shirt. In the future, we will try to extract more features so that we can measure not only t-shirts but also every type of clothes for men and women We will try to add machine learning process in our proposed model so that the system will be familiar with the environment and accurate measurement will be found out. If the result of our proposed system is quite accurate then we will try to integrate the system into the web, so that people can buy their required size clothes without going for shopping.

\section{REFERENCES}

[1] Bulgun, Ender Yazgan, and Alp Kuf. "Development of a component oriented garment design library." In International Conference on Advances in Information Systems, pp. 324-330. Springer, Berlin, Heidelberg, 2000.

[2] Mojarrad, Mousa, Amir MasoudRahmani, and MehrabMohebi. "Detection and pose estimation of people in images." World Academy of Science, Engineering and Technology 49 (2009): 985-990.

[3] Lin, Yueh-Ling, and Mao-Jiun J. Wang. "Automated body feature extraction from 2D images." Expert Systems with Applications 38, no. 3 (2011): 2585-2591.

[4] Srinivasan, Praveen, and Jianbo Shi. "Bottom-up recognition and parsing of the human body." In International Workshop on Energy Minimization Methods in Computer Vision and Pattern Recognition, pp. 153-168. Springer, Berlin, Heidelberg, 2007.

[5] Knox, A., L. J. Connell, P. Ulrich, and G. Hutton. "Body scan analysis for fit models based on body shape and posture analysis." National Textile Center Research Brief (USA). (2003).

[6] Chakraborty, Bhaskar, OgnjenRudovic, and Jordi Gonzalez. "View-invariant human-body detection with extension to human action recognition using componentwise HMM of body parts." In Automatic Face \& Gesture Recognition, 2008. FG'08. 8th IEEE International Conference on, pp. 1-6. IEEE, 2008.

[7] Black, Michael J., Oren Freifeld, Alexander W. Weiss, Matthew M. Loper, and Peng Guan. "Parameterized model of 2D articulated human shape." U.S. Patent 9,292,967, issued March 22, 2016.

[8] Wang, Charlie CL, Yu Wang, Terry KK Chang, and Matthew MF Yuen. "Virtual human modeling from photographs for the garment industry." Computer-Aided Design 35, no. 6 (2003): 577-589.

[9] Kohlschütter, Tomáš. "Human body modeling by the development of the automatic landmarking algorithm: technical report no. DCSE/TR-2012-11." (2012).

[10] Kart, Ozge, Alp Kut, ArzuVuruskan, and Ender Bulgun. "Web Based Digital Image Processing Tool for Body Shape Detection." ICT Innovations 2011, Web Proceedings ISSN 1857-7288 (2012): 139.

[11] Bălan, Alexandru O., and Michael J. Black. "The naked truth: Estimating body shape under clothing." In European Conference on Computer Vision, pp. 15-29. Springer, Berlin, Heidelberg, 2008.

[12] Nakajima, Chikahito, Massimiliano Pontil, Bernd Heisele, and Tomaso Poggio. "Full-body person recognition system." Pattern recognition 36, no. 9 (2003): 1997-2006.

[13] Artisan hut a fair trade organization. Available at: http://www.artisanhutbd.com/size-chart/ [Accessed October 20, 2018].

[14] wikiHow. Available at: https://www.wikihow.com/TakeClothing-Measurements\#Men_sub [Accessed October 22, 2018]. 


\section{Authors' Profiles}

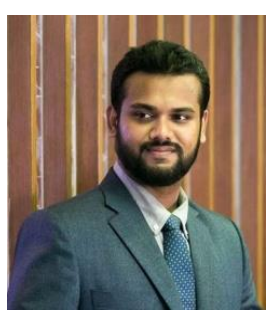

D. M. Anisuzzaman is a Lecturer in Computer Science and Engineering Department at Ahsanullah University of Science and Technology, Dhaka, Bangladesh. He has completed his M.Sc. in Computer Science from American International University - Bangladesh, Dhaka in 2018. He has received his B.Sc. from Ahsanullah University of Science and Technology, Dhaka in 2013. His research interest includes computer vision, image processing, pattern recognition, machine learning, neural network, natural language processing, and algorithms.

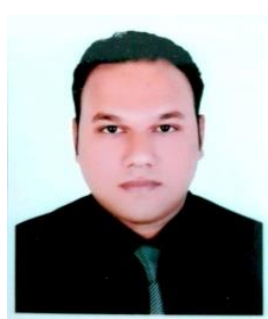

Md. Hosne Al Walid is an Assistant Professor of Computer Science and Engineering at Ahsanullah University of Science and Technology (AUST), Dhaka, Bangladesh. He obtained B.Sc. Engg. Degree in Computer Science and Information Technology from Islamic University of Technology (IUT), Gazipur, Dhaka. His current research interest includes Image Processing, Computer Vision, Human Computer Interaction (HCI) and Machine Learning.

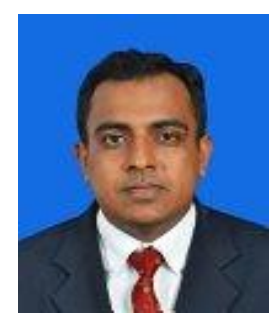

A. F. M. Saifuddin Saif received Ph.D. from Faculty of Information Science and Technology, University Kebangsaan Malaysia (UKM) in 2016. He received M.Sc. in Computer System Engineering (Software System) from University of East London, UK, and B.Sc. (Eng.) degree in Computer Science and Engineering from Shahjalal University of Science and Technology, Bangladesh in 2012 and 2008, respectively. Most of his contributions in Computer Vision and Artificial Intelligence Research field were published in ISI Q1 journals. He has published many papers in ISI indexed Journals; Scopus indexed Journals, Book Chapters, Conferences, and Proceedings. He served as Technical Committee Members, Reviewers, Guest Speakers, Session Chairs in many Conferences and Workshops. Currently, he is an Assistant Professor at Faculty of Information Science and Technology, American International University Bangladesh (AIUB). Before joining the university, he did Post Doctorate at Faculty of Information Science and Technology, University Kebangsaan Malaysia. He spent more than 6 years in IT industry such as Advanced Software Development, Web eMaze etc as IT researcher. His research interests include Image Processing, Computer Vision, Artificial Intelligence, Augmented Reality, 3D Reconstruction, and Medical Image Processing.

How to cite this paper: D. M. Anisuzzaman, Md. Hosne Al Walid, A. F. M. Saifuddin Saif, "Online Trial Room based on Human Body Shape Detection", International Journal of Image, Graphics and Signal Processing(IJIGSP), Vol.11, No.2, pp. 21-29, 2019.DOI: 10.5815/ijigsp.2019.02.03 